\title{
Correction to: How innovativeness and handedness affect learning performance of engineering students?
}

\author{
Kris M. Y. Law ${ }^{1} \cdot$ Shuang Geng ${ }^{2}$ (D)
}

Published online: 26 November 2018

(c) Springer Nature B.V. 2018

\section{Correction to: International Journal of Technology and Design Education https://doi.org/10.1007/s10798-018-9462-3}

In the original publication of the article, the affiliations of the authors have been missed to update. Now the affiliations have been provided in this correction.

The original article can be found online at https://doi.org/10.1007/s10798-018-9462-3.

Shuang Geng

gracegeng0303@163.com

Kris M. Y. Law

kris.law@polyu.edu.hk

1 Department of Industrial and Systems Engineering, The Hong Kong Polytechnic University, Kowloon, Hong Kong

2 Faculty of Technology, The University of Oulu, Oulu, Finland 